\title{
Kaidakova N.N., Skolskaya E.A., Pedorenko Y.N., Morari T.A. Application of risk assessment theory to public health when determining the size of the sanitary-protective zone in the enterprise
}

"Kazakhstan Agency of Applied Ecology" LLC

(Kazakhstan, Almaty)

doi: 10.18411/scienceconf-09-2019-23

idsp: scienceconf-09-2019-23

\section{Abstract}

This document analyzes results of software calculation of the sanitary protection zone for the oil and gas processing plant taking into account risk assessment to public health; issues were identified, and recommendations were made to improve software and regulatory documents.

Key words: public health risk assessment, sanitary protection zone, simulation of pollutant dispersion into the air, noise degeneration, and regulatory documents.

Introduction. The Health Risk Assessment Methodology from Chemical Factors of Companies was first published in 1983 by the U.S. National Research Council [4]. From 1995 to 1999, EPA - The U.S. Environmental Protection Agency trained Russian scientists in this methodology using facilities of the Institute of Human Ecology and Environmental Hygiene, Russian Academy of Medical Sciences. In 2008-2011, specialists of Kazakhstan were trained in this methodology too.

In Kazakhstan, applicable regulatory acts $[1-3,10,11]$ set the requirements to conduct a human health risk assessment, including when justifying the size of the sanitary protection zone in companies of hazard classes 1 and 2 [7, 11]. KAPE LLC has trained specialists and software to calculate health risks to public, to simulate dispersion of harmful chemicals into the air, and noise decrease during the dispersion into the local area.

The EIA projects implemented by KAPE LLC, design-basis justification of SPZ's size in the enterprise along with health risk assessment to public have positive opinions from the sanitary-epidemiological reviews of the Ministry of Public Health of the Republic of Kazakhstan. The validity of KAPE LLC's methodological approach to these issues and compliance of the work accomplished with the relevant regulatory documents has been acknowledged by the expert review opinion of the sanitary authorities of the Republic of Kazakhstan No. 07/15-7419 of July 31, 2019.

The scientific novelty of the work is that it describes the results of analysis of software and regulatory and methodological documents, provides recommendations for improvement.

The scientific and practical significance of the work is in development of recommendations to improve software and regulatory and legal documents.

The aim of the work is to analyze the results of software calculation of risk assessment to public health in compliance with the requirements of the theory of risks and to make recommendations to improve software and regulatory and legal documents.

Documents and research methods. To carry out the work, a conditional facility was selected -a designed oil and gas processing plant (analogue to an existing enterprise).

The subject of research was the regulatory framework of the Republic of Kazakhstan and the international sources under the topic of research, as well as a procedure for software calculations when simulating plant emissions dispersion, industrial noise attenuation, and health risk assessment to the population of nearby settlements (sls).

Research deliverables: results of software calculation of the population health risk assessment, statistical indices of the population health status in the sls, and pollutant emissions from the plant.

\section{Research methods:}

- Field surveys of air quality using GANG-4 instrument;

- Statistical research methods of population number, demographic indices of the state of population health, primary morbidity, and infant mortality; 
- software calculations to simulate dispersion of plant emissions, industrial noise attenuation, and population health risk assessment in the surrounding sls.

Dispersion estimations were performed by Kazakhstan Agency of Applied Ecology, LLC using the enterpise's Era software package (version 2.0). NPP Logos-Plus LLC (Novosibirsk), agreed with A.I. Voeikov Main Geophysical Observatory, which has he right to distribute it within the territory of the Republic of Kazakhstan.

Era software (version 2.0) implements "Methodology to Calculate Harmful Substances Concentrations in the Air from Enterprises' Emissions" [9].

Simulation was done in order to define the possible level of pollution from pollutant emissions of the Oil and Gas Processing Plant in the nearest sls, as well as to identify the area of pollutants impact (above-ground level concentration C> $1 \mathrm{MPC}$ ).

To assess the acoustic impact on the environment from the facilities, noise dispersion simulation was performed using Ecolog-Noise 2.0 software package, which calculated sound dispersion from external sources in compliance with Sanitary Rules and Regulations (SNiP) 2303-2003 (updated version)[5] and State Standard (GOST) 31295.1- 2005[8].

The software was developed by Integral Company, St. Petersburg, Russia. Noise impact level (acoustic) were calculated to a maximum equipment performance, taking into account its simultaneous operation. Calculations resulted in sound pressure levels in octave bands with geometric mean frequencies of $31.5-8000 \mathrm{~Hz}$, as well as the equivalent sound level La.

Estimation of the population health risk assessment was performed using Era software package, version 2.5, Era-Risks module (developed by Logos-Plus Research and Development Enterprise, Novosibirsk).

The software enables to assess the population health risk - the likelihood of development of additional adverse health effects based on calculation results of pollutant surface concentrations released into the air from a designed enterprise .

The nearest settlements from the site of the designed oil and gas processing plant (OGPP) are: sl Severny, sl Severo-Zapadny, sl Zapadny, and sl Yugo-Zapandny (Figure 1).

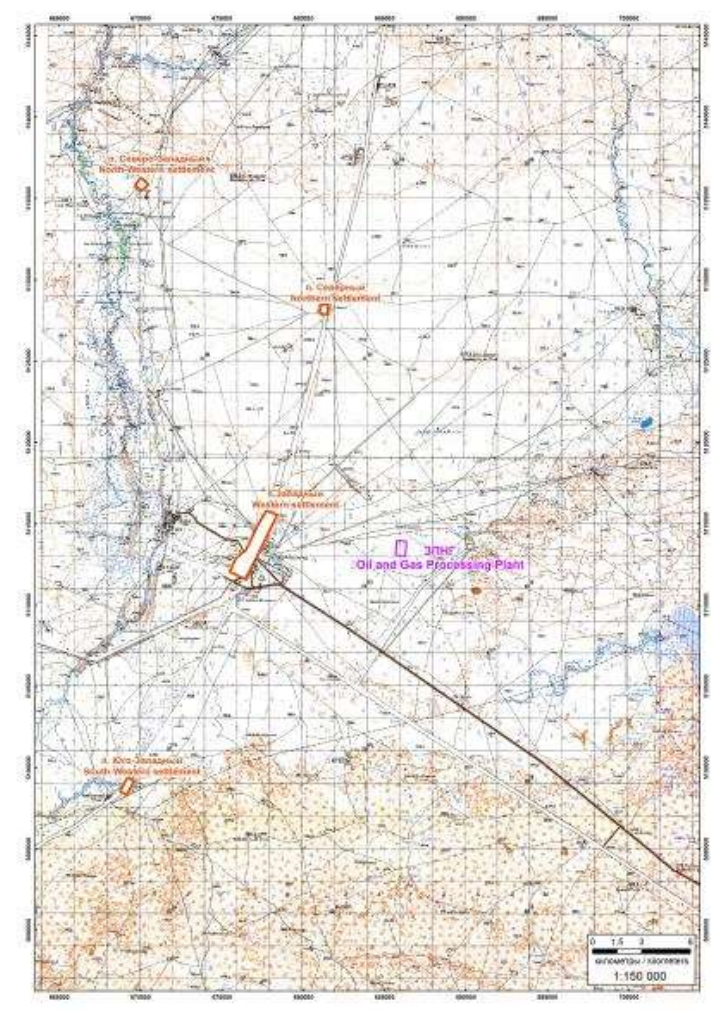

Figure1 Location of the Nearest Settlements

The distance from the plant to the nearest sls and the number of population are listed in Table 1. 


\section{Distance from the Plant to the Nearest Sls}

Table 1

Settlement
v. Severny
v. Severo-Zapadny
v. Zapadny
v. Yugo-Zapandny

Distance, km

14.8

26.7

7.5

21.3
Number of people

residing in

settlement as of

January 01. 2018

$\begin{array}{cc}9000 & +32 \\ 5000 & +22 \\ 10000 & -3 \\ 9000 & +6\end{array}$

\author{
Changes in numbers for \\ 2016-2018 \\ $+32$ \\ $+22$ \\ $+6$
}

The largest settlement amongst those under review - sl Zapadny and the smallest one - sl Severo-Zapadny.

In 2016-2018, the population increased in sl Severny (especially significantly), in sl Severo-Zapadny (to a lesser extent), and in sl Yugo-Zapandny (only slightly), and in sl Zapadny, population declined slightly. nearest sls.

Air quality was surveyed at 6 sites. Sites were selected in the projected area, and in the

In accordance with SR No. 237 [7], when determining the Sanitary Protection Zone size, it shall be required to comply with the established hygienic standards for the air quality, physical effects (noise, electromagnetic radiation, and etc.), and the acceptable level of human health risk at its border.

The minimum standard size for SPZ (5000 m) established in SR No. 237 [7] should be confirmed or adjusted (increased if it is technically impossible to mitigate pollutant emissions).

\section{Research results.}

To calculate the risks to public health from plant emissions, the social and demographic conditions and a morbidity rate of the population in the nearest sls prior to the plant construction were surveyed; and a potential impact of air pollution on morbidity was assessed.

Demographic indices of the population health are characterized by an increase in the birth rate of population in all sls for 2016-2018. The region and district recorded a rise in the birthrate too. As for the Republic of Kazakhstan, the birth rate had a stable level. A decrease in the mortality rate for the analyzed period is recorded in all sls. As for the district, region and nationwide, rates of decline in population level is less noticeable. Natural population growth for 2008-2010 has increased in all sls. The natural population growth in the Republic tended to increase over the past three years, and a statistically significant increase was recorded in the region and district.

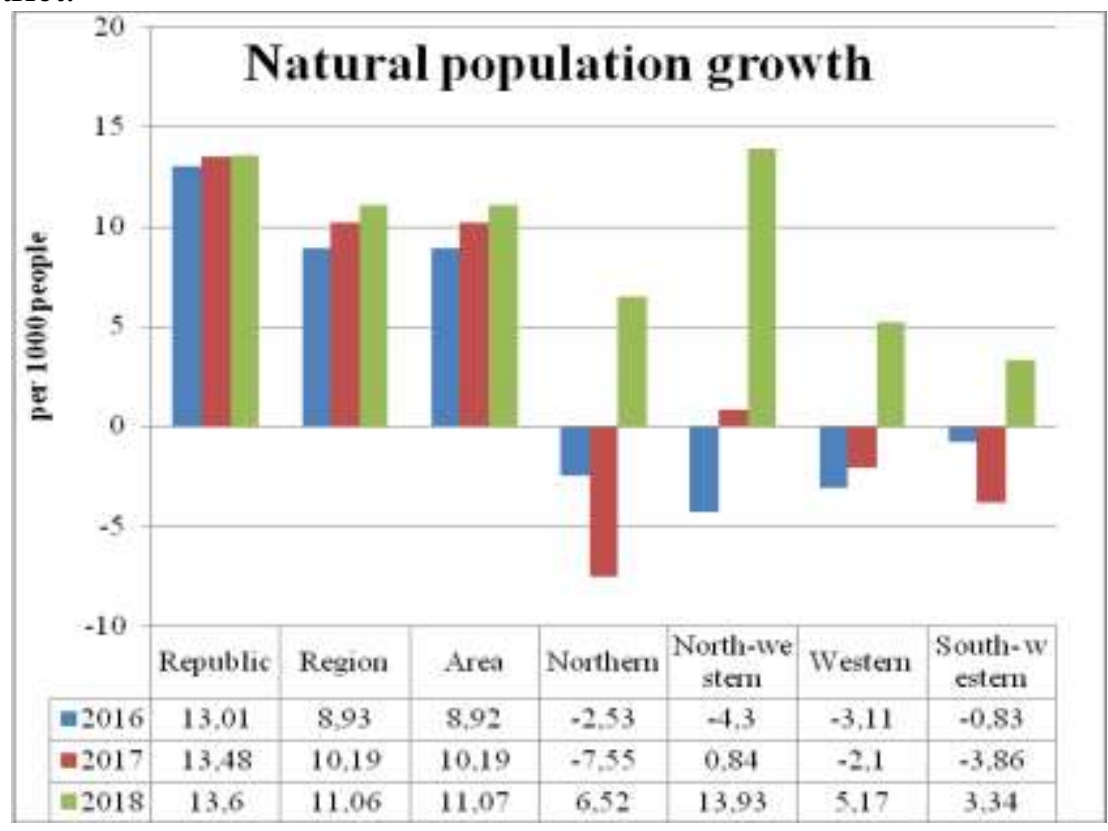

Figure 2. Natural Population Growth 
Cases of infant mortality during the survey period were recorded in sls Severny, SeveroZapadny, and Zapadny. The indices were higher than in the district, region and country. Fertility rates in the surveyed sls are primarily higher too than across the district, region, and country. The primary morbidity of the entire population and the primary morbidity of respiratory diseases in sls near the plant boundary (sls Severny, Severo-Zapadny, Zapadny, Yugo-Zapadny for the entire observation period was significantly lower than in the country, region, and district (Table 2).

Table 2

Primary Morbidity of Respiratory Dseases (number of diseases recorded for the first time in life, per 100,000 people of relevant population)

\begin{tabular}{|c|c|c|c|c|c|c|c|c|c|c|c|c|}
\hline \multirow{2}{*}{ Location } & \multicolumn{4}{|c|}{2016} & \multicolumn{4}{|c|}{2017} & \multicolumn{4}{|c|}{2018} \\
\hline & Total & \begin{tabular}{|l|} 
Adults \\
\end{tabular} & Teens & 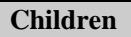 & Total & Autints & Teens & Children & Total & \begin{tabular}{|l|} 
Adults \\
\end{tabular} & Teens & Children \\
\hline Republic & 22957.3 & 11078.2 & 30732.1 & 55972.6 & 24535.5 & 11384.1 & 35932.3 & 60302.1 & 23575.3 & 10647.7 & 33038.1 & 58959.2 \\
\hline Region & 20679.4 & 7103.7 & 22490.7 & 64485.3 & 21306.6 & 7356.7 & 28055.6 & 65335.8 & 18908.8 & 6729.1 & 27177.6 & 57336.3 \\
\hline Area & 17863.0 & 7219.8 & 18482.1 & 45216.0 & 17022.1 & \begin{tabular}{|l|}
7363.0 \\
\end{tabular} & 28929.1 & 39816.8 & 15027.8 & 7082.1 & 26384.2 & 34649.9 \\
\hline Northern & 10865.4 & 4687.5 & 20300.8 & 22770.0 & 12613.3 & 4428.9 & 25454.5 & 28370.8 & 20047.4 & \begin{tabular}{|l|}
8769.2 \\
\end{tabular} & 65573.8 & 56615.4 \\
\hline North-western & 11908.2 & 2823.8 & 15384.6 & 43252.6 & 14728.0 & 3522.7 & 10447.8 & 55645.2 & 16495.6 & 2192.6 & 59701.5 & 65322.6 \\
\hline Western & 6152.9 & 9401.7 & 3260.9 & 24425.3 & 7417.8 & 96.4 & 3658.5 & 32903.2 & 15394.6 & 912.1 & 1639.3 & 81003.6 \\
\hline South- western & \begin{tabular}{|l|}
9571.0 \\
\end{tabular} & 1713.1 & 4166.7 & 47087.4 & 19907.4 & 1200.0 & 3896.1 & 110958.9 & 53229.4 & 4111.6 & 300000.0 & 197449.0 \\
\hline
\end{tabular}

The survey showed high air quality in the region of planned construction of the plant. Concentrations of all observed substances (except for dust, suspended particles) are below a detection limit, according to GANK-4 device, or at a minimal detection level. Concentration of dust (suspended particles) in case of light winds did not exceed 13\% of MPCm.o.t., which also indicates a low level of dust pollution during the observation period.

During the regular operation of the enterprise, air emissions comprising 40 pollutants of hazard classes 1-4 from stationary sources were identified. A total of 10334.81 tons/year of air pollutant emissions are expected. Air pollutant emissions include 8 groups of substances that have a cumulative impact effect. Above-ground level concentration was simulated for all pollutants and cumulative groups.

To establish the border and the size of the SPZ enterprise, the estimations were carried out:

- maximum single (average for 20-30 minutes) pollutant concentrations in the air;

- dimensionless cumulative single concentrations of substances in the air belonging to groups of combined harmful effect "q" (total summation, incomplete summation, potentiation);

- average annual pollutant concentrations in the air to be defined taking into account the unsteadiness (instability over time) of weather conditions, capacities, and any other parameters from emission sources.

It was identified that the pollution area according to the maximum single and average annual concentrations during the regular operation of the planned plant does not exceed the minimum standard size of SPZ - 5000m, set in SR No. 237 [7].

The simulation results of noise dispersion showed that the maximum distance from the outmost noise source of the plant to isoline $55 \mathrm{~dB}$ ( 1 Maximum Permissible Level for daytime) is 605 meters; to isoline $45 \mathrm{~dB}$ (Maximum Permissible Level for night time) - $1146 \mathrm{~m}$ (Figure 3). Thus, no adjustments to the minimum standard size of SPZ - $5000 \mathrm{~m}$, are required. 


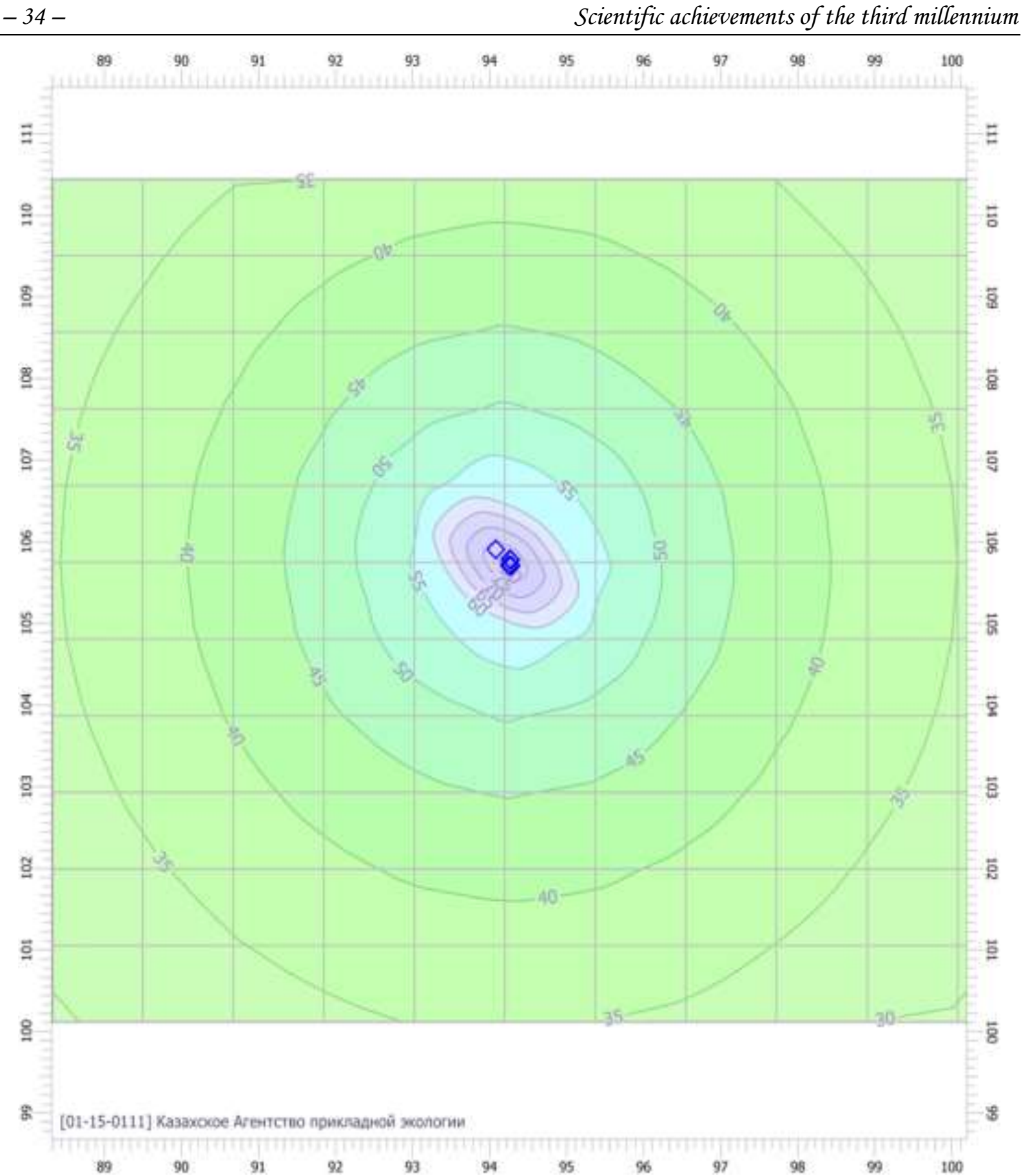

Figure 3. Decrease in Sound Pressure (Noise Level) Depending on the Distance from the Outmost Sources of Primary Noise Generating Facilities of the Plant

Estimations showed that SPZ size in terms of physical impact (noise) level is less than SPZ size in terms of chemical impact (air pollution with harmful substances).

Thus, it was found that pollutant emissions from a designed oil and gas processing plant when dispersed into the air will not exceed hygienic standards for air quality and levels of physical impact (MPC and MPL) at the nearest sls. Considering that the estimated impact areas (C) MPC) of the maximum single and average annual concentrations for all pollutants and summation groups, as well as the acoustic impact areas (C> MPL) do not exceed the SPZ size, according to the sanitary classification of industrial facilities [7], adjustments/increase in the minimum standard size of SPZ - 5000m - is not required.

To assess the risk to public health, pollutants emitted from the enterprise, were explored from the position of their carcinogenic and non-carcinogenic acute and chronic impact on population's morbidity of nearby sls. Out of 40 identified substances emitted into the air, carcinogenic properties were defined for 4 substances [6] (Table 3) 
Information of Hazard Parameters of Carcinogenic Effects

\begin{tabular}{|c|c|c|c|c|c|}
\hline \multirow{2}{*}{ Substance } & \multirow{2}{*}{ CAS } & \multicolumn{3}{|c|}{ Inhalation exposure } \\
\cline { 4 - 6 } & & IARC & ERA & $\begin{array}{c}\text { SFi, (kg x } \\
\text { day)/mg }\end{array}$ & $\begin{array}{c}\text { Uri, } \\
\mathbf{~ m} / \mathbf{m g}\end{array}$ \\
\hline \hline 1. [0328] Soot & $1333-86-4$ & 1 & & 3.1 & 0.9424 \\
\hline 2. [0703] Benzapiren & $50-32-8$ & $2 \mathrm{~A}$ & $\mathrm{~B} 2$ & 3.1 & 0.9424 \\
\hline $\begin{array}{c}\text { 3. [0906] Tetrachloromethane (Carbon tetrachloride, } \\
\text { Carbon tetrachloride) (546) }\end{array}$ & $56-23-5$ & $2 \mathrm{~B}$ & $\mathrm{~B} 2$ & 0.053 & 0.016112 \\
\hline 4. [0602] Benzene & $71-43-2$ & 1 & $\mathrm{~A}$ & 0.027 & 0.008208 \\
\hline
\end{tabular}

For notes look under Table 4.4 Manuals[12]

The greatest carcinogenic hazard according to IARC, out of substances listed in Table 3, is Soot and Benzene, which classify as carcinogenic hazard class 1. According to the carcinogenic potential factor, that is, taking into account the ratio of the emissions volume and carcinogenic hazard of a substance, the most carcinogenic hazard is soot and benzpyrene (cumulatively, produce $98.43 \%$, which is more than 95\% HRIc). Contribution of the remaining carcinogens to the cumulative index of comparative carcinogenic hazard were relatively low.

Ranking of priority carcinogens is specified in Table 4.7 of the Manual [12]; results are listed in Table 4.

Table 4

Priority Pollutants-Cancerogenes

\begin{tabular}{|c|c|c|c|c|}
\hline \hline Substance & $\begin{array}{c}\text { Cmax (average } \\
\text { annual), } \mathbf{m g} / \mathbf{m}^{\mathbf{3}}\end{array}$ & $\begin{array}{c}\text { Gross emissions, } \\
\text { t/year }\end{array}$ & MPC d.a., $\mathbf{m g} / \mathbf{m 3}$ & $\begin{array}{c}\text { Comparative Hazard Index, } \\
\text { HRIc }\end{array}$ \\
\hline \hline 1. [0328] Soot & 0.000007 & 52.438 & 0.05 & 0.02 \\
\hline $\begin{array}{c}\text { 2. [0703] Benzapiren } \\
\begin{array}{c}\text { (Carbo6] Tetrachloromethane tetrachloride, } \\
\text { Carbon tetrachloride) (546) }\end{array}\end{array}$ & 0.0 & 0.000606 & 0.000001 & 0.01 \\
\hline 4. [0602] Benzene & 0.0 & 0.0155 & 0.7 & 0.001 \\
\hline
\end{tabular}

According to the carcinogenic hazard, the rankings of potential hazardous substances in the plant's region are distributed as follows: 1 - soot, 2 - benzpyrene, 3 - carbon tetrachloride, and 4 - benzene.

According to the results of pre-ranking and due to the high risk of carcinogens to health, all 4 cancerogenes were included in the subsequent risk assessment.

At the stage of hazard identification, availability of data on reference levels during acute and chronic impacts from chemicals was analyzed, and a "priority (short) list" of pollutants was compiled. It was found that the following substances make the largest part of the gross pollutant emissions:

- $\quad$ carbon monoxide - $38.9 \%$,

- $\quad$ sulfur dioxide $-28.1 \%$,

- $\quad$ nitrogen dioxide $-24.8 \%$,

- $\quad$ nitric oxide $-4.0 \%$.

Gross emissions of these substances are $95.79 \%$. The upper confidence interval is observed - at least $95 \%$. Thus, these substances are priority in terms of gross emissions.

It should be noted that an estimated risk assessment was made not only for "priority" substances, but also for all 40 substances contained in the enterprise's emissions .

Risk profile for development of non-carcinogenic effects during acute and chronic impacts for each substance was formed on the basis of calculation of the hazard factor (Section 7.3 of the Manual) [12] .

These date enabled to compile a List of Priority Pollutants-Non-Carcinogens of Acute (Table 5) and Chronic (Table 6) Impact, and to rank them.

Non-Carcinogen Ranking 
Ranking of non-carcinogens was done according to Section 4.7 of the Manual [12]. Ranking of acute impact non-carcinogens, according to the hazard index, showed that all pollutants contained in the List of Pollutants subject to in-depth analysis had a HRI index of $\leq 0.01$ (Table 5).

Table 5

Ranking of Priority Acute Impact Pollutants-Non-Carcinogens According to Comparative NonCarcinogenic Hazard Index

\begin{tabular}{|c|c|c|c|c|c|}
\hline Substance & $\begin{array}{c}\mathrm{Cmax}(\max \\
\text { times), } \mathrm{mg} / \mathrm{m} 3\end{array}$ & $\begin{array}{c}\text { Gross } \\
\text { emissions, } \\
\text { t/year }\end{array}$ & $\begin{array}{c}\text { MPCm.o.t. } \\
\mathrm{mg} / \mathrm{m3}\end{array}$ & $\begin{array}{l}\mathrm{ARFC} \\
\mathrm{mg} / \mathrm{m} 3\end{array}$ & $\begin{array}{l}\text { HRI, } \\
\text { index }\end{array}$ \\
\hline $\begin{array}{l}\text { 7. [0150] Sodium hydroxide (Caustic } \\
\text { soda, Caustic soda) (876) }\end{array}$ & - & 0,00251 & - & 0.005 & 0.01 \\
\hline 3. [0333] Hydrogen sulfide & 0.002134 & 30,583 & 0.008 & 0.1 & 0.002 \\
\hline 2. [0602] Benzene & - & 0.0079 & 0.3 & 0.15 & 0.001 \\
\hline 4. [1728] Ethyl mercaptan & 0.000003 & 0,05429 & 0.00005 & 0.1 & 0.001 \\
\hline 5. [0322] Sulfuric acid (517) & 0.000024 & 0.6656 & 0.3 & 0.1 & 0.001 \\
\hline 14. [0302] Nitric acid (5) & - & 0.0158 & 0.4 & 0.09 & 0.001 \\
\hline 8. [0330] Sulfur dioxide * & 0,02238 & 2905,771 & 0.5 & 0.66 & 0,0004 \\
\hline 9. [0301] Nitrogen dioxide * & 0,068012 & 2558,733 & 0.2 & 0.47 & 0,0004 \\
\hline 10. [0304] Nitric oxide $*$ & 0.011052 & 415,795 & 0.4 & 0.72 & 0,0003 \\
\hline $\begin{array}{l}\text { 1. [0906] Tetrachloromethane (Carbon } \\
\text { tetrachloride, Carbon tetrachloride ) (546) }\end{array}$ & - & 0.0155 & 4.0 & 1.3 & 0.0001 \\
\hline \begin{tabular}{|l|} 
6. [0348] Phosphoric acid (938) \\
\end{tabular} & - & 0,000044 & - & 0.2 & 0.0001 \\
\hline $\begin{array}{l}\text { 16. [1078] Ethane-1,2-diol (Glycol, } \\
\text { Ethylene Glycol) (1444) }\end{array}$ & 0.0013 & 1,361 & - & 1.3 & 0.0001 \\
\hline 20. [0337] Carbon oxide * & 0,0311 & 4018,726 & 5,0 & 23.0 & 0.00004 \\
\hline 11. [0616] Xylene & 0,000294 & 0.2468 & 0.2 & 4.3 & 0.00001 \\
\hline \begin{tabular}{|c|} 
12. [0316] Hydrochloride (Hydrochloric \\
acid, Hydrogen chloride) (163)
\end{tabular} & - & 0.0041 & 0.2 & 2.1 & 0.00001 \\
\hline 13. [0303] Ammonia (32) & 0.000352 & 3,688 & 0.2 & 3.0 & 0.00001 \\
\hline 15. [1555] Acetic acid & 0.000148 & 0.5199 & 0.2 & 3,7 & 0.00001 \\
\hline 17. [0621] Toluene & - & 0.0026 & 0.6 & 3.8 & 0.00001 \\
\hline 18. [1401] Propan-2-one (Acetone) (470) & - & 0,0202 & 0.35 & 62.0 & 0.00001 \\
\hline 19. [1052] Methyl alcohol & 0,00035 & 4,837 & 1,0 & 30,0 & 0.00001 \\
\hline
\end{tabular}

* Makes up the priority in terms of contribution to gross emissions

The low comparative non-carcinogenic hazard index does not make it possible to include all pollutants specified in Table 5 in the List of Substances subject to in-depth analysis (HRI index $\leq 0.01$ ).

Ranking results of chronic impact non-carcinogens according to the hazard index found only 1 substance [0703] Benzo/a/pyrene, which had an index equal to 1.0; 4 substances with a 0.2-0.1 index ([0333] Hydrogen sulfide, [1728] Ethyl mercaptan, [1715] Methyl mercaptan, [0322] Sulfuric acid (517) (Table 6).

Table 6

Priority Chronic Impact Non-Carcinogens-Pollutants

\begin{tabular}{|c|c|c|c|c|c|}
\hline Substance & $\begin{array}{c}\text { Cmax (average } \\
\text { per year), mg/m3 } 3\end{array}$ & $\begin{array}{c}\text { Gross } \\
\text { emissions, } \\
\text { t/year }\end{array}$ & $\begin{array}{c}\text { MPCa.d, } \\
\mathbf{m g} / \mathbf{m 3}\end{array}$ & $\begin{array}{c}\text { ARFC, } \\
\mathbf{m g} / \mathbf{m 3}\end{array}$ & $\begin{array}{c}\text { HRI, } \\
\text { index }\end{array}$ \\
\hline \hline 2. [0703] Benzo/a/pyrene & 0.0 & 0.000606 & 0.000001 & 0.000001 & 1.0 \\
\hline 5. [0333] Hydrogen sulfide & 0.000281 & 30.583 & - & 0.001 & 0.2 \\
\hline 6. [1728] Ethyl mercaptan & 0.0 & 0.05429 & - & 0.001 & 0.1 \\
\hline 7. [1715] Methyl mercaptan & 0.000001 & 0.105696 & - & 0.001 & 0.1 \\
\hline 8. [0322] Sulfuric acid (517) & 0.000005 & 0.6656 & 0.1 & 0.001 & 0.1 \\
\hline $\begin{array}{c}\text { 9. [0708] Naphthalene ( Platidiam, Cisplatin ) } \\
\text { (416) }\end{array}$ & 0.000002 & 0.1967 & - & 0.003 & 0.01 \\
\hline
\end{tabular}




\begin{tabular}{|c|c|c|c|c|c|}
\hline $\begin{array}{l}\text { 10. [0626] 1,2,4-Trimethylbenzene ( } \\
\text { Pseudocumene ) (569) }\end{array}$ & 0.000001 & 0.1023 & 0.015 & 0.006 & 0.01 \\
\hline 11. [0348] Ortho-phosphoric acid (938) & 0.0 & 0.000044 & - & 0.01 & 0.01 \\
\hline $\begin{array}{c}\text { 12. [0150] Sodium hydroxide (Caustic soda) } \\
\text { (876) }\end{array}$ & 0.0 & 0.00251 & - & 0.002 & 0.01 \\
\hline 13. [0330] Sulfur dioxide* & 0.000265 & 2905.771 & 0.05 & 0.08 & 0.004 \\
\hline 14. [0301] Nitrogen dioxide* & 0.001771 & 2558.733 & 0.04 & 0.04 & 0.004 \\
\hline 15. [0304] Nitric oxide* & 0.000288 & 415.795 & 0.06 & 0.06 & 0.003 \\
\hline 1. [0328] Soot & 0.000008 & 52.438 & 0.05 & 0.05 & 0.002 \\
\hline $\begin{array}{l}\text { 3. [0906] Tetrachloromethane (Carbon } \\
\text { tetrachloride) (546) }\end{array}$ & 0.0 & 0.0155 & 0.7 & 0.04 & 0.001 \\
\hline 4. [0602] Benzene & 0.0 & 0.0079 & 0.1 & 0.03 & 0.001 \\
\hline 16. [2735] Mineral oil & 0.000016 & 2.542 & - & 0.05 & 0.001 \\
\hline $\begin{array}{l}\text { 17. [1880] Di (2-hydroxyethyl ) amine } \\
\text { ( diethanolamine ) (367) }\end{array}$ & 0.000025 & 2.609 & - & 0.02 & 0.001 \\
\hline 19. [0616] Xylene & 0.000002 & 0.2468 & - & 0.1 & 0.001 \\
\hline $\begin{array}{l}\text { 20. [0316] Hydrochloride (Hydrochloric acid, } \\
\text { Hydrogen chloride) (163) }\end{array}$ & 0.0 & 0.0041 & 0.1 & 0.02 & 0.001 \\
\hline 21. [0303] Ammonia (32) & 0.000035 & 3.688 & 0.04 & 0.1 & 0.001 \\
\hline 22. [0302] Nitric acid (5) & 0.0 & 0.0158 & 0.15 & 0.04 & 0.001 \\
\hline 23. [1555] Acetic acid & 0.000005 & 0.5199 & 0.06 & 0.25 & 0.0001 \\
\hline $\begin{array}{l}\text { 24. [1078] Ethane-1.2-diol (Glycol, Ethylene } \\
\text { Glycol) (1444) }\end{array}$ & 0.000013 & 1.361 & - & 0.4 & 0.0001 \\
\hline 25. [0621] Toluene & 0.0 & 0.0026 & - & 0.4 & 0.0001 \\
\hline 26. [0370] Carbon sulfide & 0.000001 & 0.086759 & - & 0.3 & 0.0001 \\
\hline 31. [0337] Carbon monoxide* & 0.0024 & 4018.726 & 3.0 & 3.0 & 0.00004 \\
\hline 30. [0410] Methane & 0.000003 & 25.268 & - & 50.0 & 0.00002 \\
\hline 18. [1042] Butan-1-ol (Butyl alcohol) (102) & 0.000002 & 0.1887 & - & 2.06 & 0.00001 \\
\hline 27. [1401] Propan-2-one (Acetone) (470) & 0.0 & 0.0202 & - & 31.2 & 0.00001 \\
\hline 28. [1061] Ethanol (Ethyl alcohol) (667) & 0.0 & 0.0536 & - & 100.0 & 0.00001 \\
\hline 29. [1052] Methyl alcohol & 0.000045 & 4.837 & 0.5 & 4.0 & 0.00001 \\
\hline
\end{tabular}

* Makes up the priority in gross emissions

The priority compounds from the list of substances with non-carcinogenic properties are hydrogen sulfide (hazard indices for acute and chronic impact - 0.02 and 0.2), sulfur dioxide (0.0004 and 0.004), nitrogen dioxide (0.0004 and 0.004), nitrogen oxide (0.0003 and 0.003$)$, and carbon monoxide (0.00004 and 0.00004).

Thus, after identification, ranking of all emissions from plant's facilities, assessment of impact routes, it would be possible to make up a list of priority compounds for further analysis:

1. Carcinogenic risk to public health was assessed for 4 substances (benzo/a/pyrene, soot, benzene, carbon tetrachloride), and according to the ranking results, the most carcinogenic hazardous substances among them were soot and benzo/a/pyrene.

2. Priority compounds from the list of substances with non-carcinogenic properties are hydrogen sulfide, sulfur dioxide, nitrogen dioxide, nitric oxide, and carbon monoxide.

3. The primary way of pollutants impact emitted from the plant on population health of nearby sls is through inhalation.

To assess the "dose-response" relationship, a MPC system and EPA procedure (USA) were used, which made it possible to remove 8 substances, for which the data on harmful effects were not available, from the initially reviewed list (40 substances). Further, a "short list" of specific emissions was compiled. This List included 4 substances with a proportion of $95.79 \%$. Carcinogenic effects were defined for 4 substances. 
Reference concentrations for chronic inhalation exposure were defined for 29 substances; for acute exposure - 12 substances, and 9 substances did not have a reference concentration.

Of the specified list of substances, 21 substances were acute impact non-carcinogens, of which 13 substances had harmful effects on the respiratory system, 4 - on the central nervous system, 3 - on human development, 2 - on eyes, 1 - on the cardiovascular system, liver, reproductive and immune systems, and kidneys.

Chronic impact non-carcinogens - 32 substances, of which 20 substances had harmful effects on the respiratory system, 10 - on the Central Nervous System, human development, 6 on kidneys, 5 - on blood, cardiovascular system, 4 substances - on liver, 3 - on the immune system, 2 - on eyes, 1 substance - biochemical effects, systemic diseases, nervous system, teeth, red bone marrow, reproductive system, and mortality.

Thus, respiratory organs are most critical by hazard development of non-carcinogenic effects from the reviewed substances in plant's emissions, in compliance with set reference concentrations for both acute and chronic inhalation exposures.

Exposure assessment is definition of real chemical pressures for the population from a designed plant's emissions.

The project provides for assessment of penetration of chemical substances from a conventional plant's emissions from only one contaminated transporting and directly impacting environment - air, and through one route of penetration - inhalation, which is permissible. A conventional plant's emissions exposure was assessed at 4 calculation points in the nearest sls.

Calculation point 3 (sl Zapadny) is located in the vicinity of the outmost sources of emissions compared to other fixed points. The exposed group comprises the entire population of sls. The maximum daily exposure is assumed to be 24 hours.

Table 7 lists features of carcinogenic risk at fixed (estimated) observation point 3 closest to the plant - sl Zapadny.

Table 7

Carcinogenic Risk Features in Sl Zapadny

\begin{tabular}{|c|c|c|c|c|c|}
\hline \multirow{2}{*}{ Observation points } & \multicolumn{2}{|c|}{ Coordinates } & \multirow{2}{*}{$\begin{array}{c}\mathrm{C}, \\
\mathrm{mg} / \mathrm{m3}\end{array}$} & \multirow{2}{*}{ LADD mg/(kg x day $)$} & \multirow{2}{*}{ CR } \\
\hline & $\mathrm{X}$ & $\mathrm{Y}$ & & & \\
\hline $\begin{array}{l}\text { Settlement point 3: sl Zapadny - the point of } \\
\text { maximum impact }\end{array}$ & 77090 & 113815 & & & \\
\hline \multicolumn{3}{|l|}{1, [0328] Soot } & $7,5 \mathrm{E}-6$ & $2,19 \mathrm{E}-6$ & $6,78 \mathrm{E}-6$ \\
\hline \multicolumn{3}{|l|}{ 2, [0602] Benzene } & $3,11 \mathrm{E}-8$ & 9,07E-9 & $2,45 \mathrm{E}-10$ \\
\hline \multicolumn{3}{|l|}{ 3, [0703] Benzo/a/pyrene } & $5,1 \mathrm{E}-10$ & $1,49 \mathrm{E}-10$ & $4,61 \mathrm{E}-10$ \\
\hline \multicolumn{3}{|c|}{ 4, [0906] Tetrachloromethane (Carbon tetrachloride) (546) } & $6,1 \mathrm{E}-8$ & $1,78 \mathrm{E}-8$ & $9,43 \mathrm{E}-10$ \\
\hline \multicolumn{5}{|c|}{ No organotropy } & $9,43 \mathrm{E}-10$ \\
\hline \multicolumn{5}{|c|}{ respiratory system } & $4,61 \mathrm{E}-10$ \\
\hline \multicolumn{5}{|c|}{ leather } & $6,78 \mathrm{E}-6$ \\
\hline \multicolumn{5}{|c|}{ lungs } & $6,78 \mathrm{E}-6$ \\
\hline \multicolumn{5}{|c|}{ stomach } & $4,61 \mathrm{E}-10$ \\
\hline \multicolumn{5}{|c|}{ hematopoietic system } & $2,45 \mathrm{E}-10$ \\
\hline
\end{tabular}

At all observation points, the individual carcinogenic risk of substances under review, and the maximum levels of exposure to human organs do not exceed the lower limit of acceptable level $-1 \times 10^{-6}$.

Estimation results of the non-carcinogenic risk of acute exposure for population health in sl Zapandy, closest to the plant, are listed in Table 8.

Table 8

Maximum Acute Non-Carcinogenic Exposure Features in Sl Zapandy

\begin{tabular}{|c|c|c|c|c|}
\hline \multirow{2}{*}{ Observation points } & \multicolumn{2}{|c|}{ Coordinates } & \multirow{2}{*}{$\mathbf{A C}, \mathbf{m g} / \mathbf{m} \mathbf{3}$} & \multirow{2}{*}{ HQ(HI) } \\
\cline { 2 - 5 } & $\mathbf{X}$ & $\mathbf{Y}$ & & \\
\hline $\begin{array}{c}\text { Western settlement point 3: point of } \\
\text { maximum non-carcinogenic acute } \\
\text { exposure }\end{array}$ & 77090 & 113815 & & \\
\hline
\end{tabular}




\begin{tabular}{|c|c|c|}
\hline [0301] Nitrogen dioxide & 0.068012 & 0.144706 \\
\hline [0303] Ammonia (32) & 0.000352 & 0.000117 \\
\hline [0304] Nitric oxide & 0.011052 & 0.01535 \\
\hline [0322] Sulfuric acid (517) & 0.000024 & 0.00024 \\
\hline$[0328]$ Soot & 0.000134 & 0.00089 \\
\hline [0330] Sulfur dioxide & 0.02238 & 0.033909 \\
\hline [0333] Hydrogen sulfide & 0.002134 & 0.021345 \\
\hline [0337] Carbon oxide & 0.0311 & 0.001352 \\
\hline [0616] Xylene & 0.000294 & $6.84 \mathrm{E}-05$ \\
\hline [0626] 1,2,4-Trimethylbenzene ( Pseudocumene ) (569) & $5.6 \mathrm{E}-06$ & 0.00014 \\
\hline [0708] Naphthalene ( Platidiam, Cisplatin ) (416) & $1.1 \mathrm{E}-05$ & 0.00157 \\
\hline [1042] Butan-1-ol (Butyl alcohol) (102) & 0.00001 & 0.0001 \\
\hline [1052] Methyl alcohol & 0.00035 & $1.17 \mathrm{E}-05$ \\
\hline [1078] Ethane-1,2-diol (Glycol, Ethylene Glycol) (1444*) & 0.0013 & 0.001 \\
\hline$[1555]$ Acetic acid & 0.000148 & 0.00004 \\
\hline [1715] Methyl mercaptan & $5.4 \mathrm{E}-06$ & 0.0009 \\
\hline [1728] Ethyl mercaptan & $2.78 \mathrm{E}-06$ & $2.78 \mathrm{E}-05$ \\
\hline \multicolumn{2}{|l|}{ respiratory system } & 0.215804 \\
\hline \multicolumn{2}{|l|}{ cardiovascular system } & 0.001352 \\
\hline \multicolumn{2}{|l|}{$\mathrm{CNS}$} & $8 \mathrm{E}-05$ \\
\hline \multicolumn{2}{|l|}{ development } & 0.001352 \\
\hline \multicolumn{2}{|l|}{ the kidneys } & 0.001 \\
\hline \multicolumn{2}{|l|}{ eyes } & 0.000186 \\
\hline
\end{tabular}

Acute non-carcinogenic risk of all substances across all observation points was less than 1.0 .

The organ that was mostly exposed to emissions was the respiratory system.

Thus, the hazard factors for acute non-carcinogenic risk exposure for all substances at all 4 fixed observation points was less than 1.0, which corresponds to the minimum risk level of harmful effects (MR, 2004) [1].

The hazard factors for chronic non-carcinogenic risk exposures for all substances (HQ) and human organs in all human sls does not exceed a unit. The likelihood of development of harmful effects with an individual during daily penetration of these substances throughout his/her life is insignificant, and this impact is characterized as permissible.

Due to the fact that the likelihood of development of harmful effects with the population of nearby sls during daily penetration of all reviewed substances throughout their lifetime is insignificant, and this impact is considered to be permissible; it is not required to define a risk mitigation strategy. Industrial monitoring of air pollutant emissions is an adequate measure of risk control.

\section{Definition of SPZ size based on risk estimation to public health}

Based on estimations (Era-Risks software), schematic maps with estimated areas of permissible carcinogenic, non-carcinogenic acute and chronic risks to public health were made. The external contour of these isolines is estimated SPZ, according to the final health risk assessment.

Figure 4 shows the final estimation rationale for SPZ size, according to hygienic standards: Maximum Permissible Concentration, Maximum Permissible Level, and human health risk assessment. 


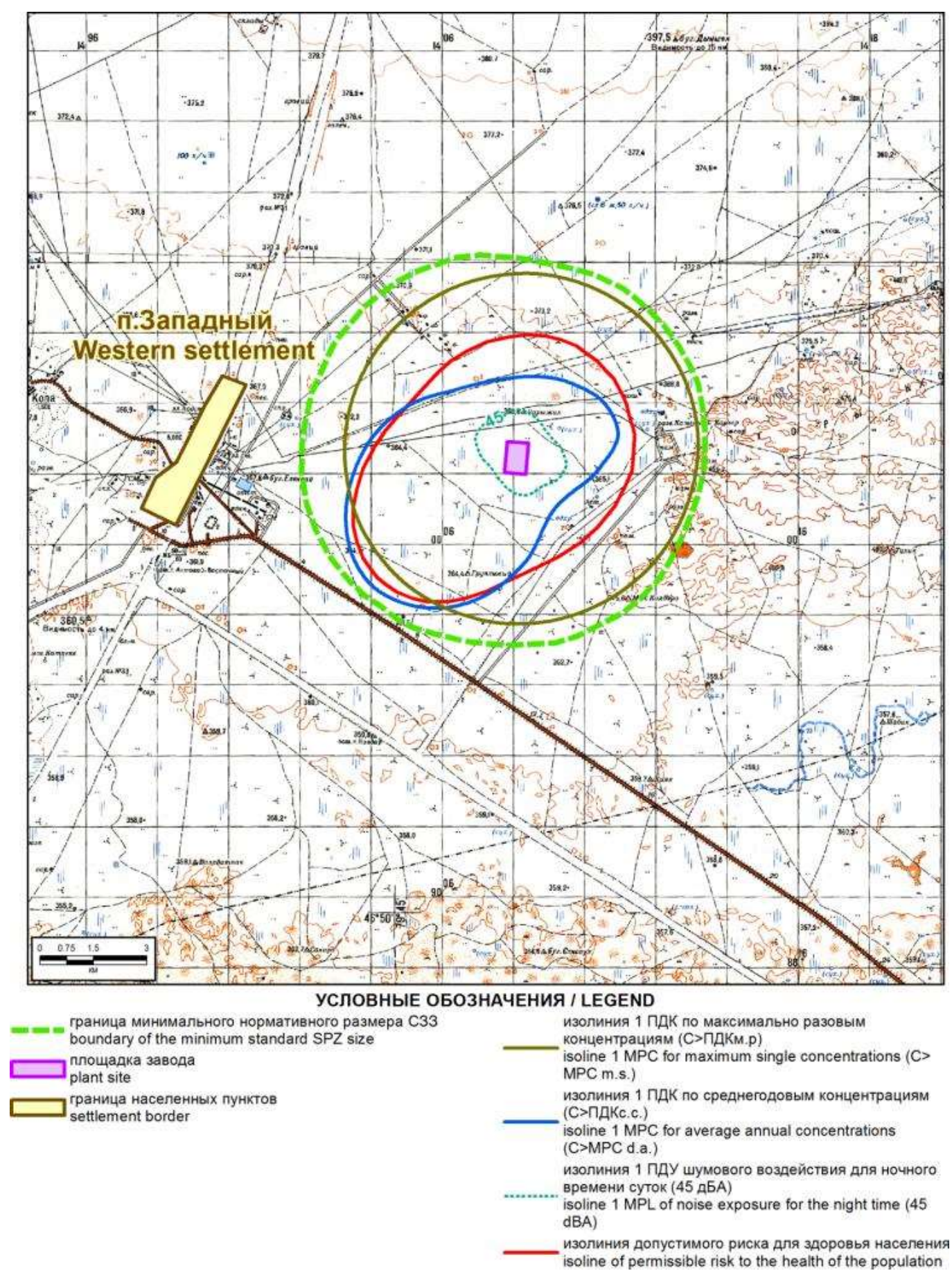

Figure 4 Estimated substation of the size of SPZ size for hygienic standards (MPC, MPL) and human health risk assessment

Thus, under normal operational conditions of a design plant, doses of priority pollutants penetration into the body do not pose health hazards to the population of nearby sls to the plant. The value of individual carcinogenic risk in sls Zapandy and Yugo-Zapadny is estimated as permissible - the upper limit of acceptable risk (less than $10^{-4}$ ), while in sls Severno-Zapandy and Severny is estimated as acceptable (at the level of $10^{-6}$ ). The hazard factors of non-carcinogenic risk of acute and chronic exposures for all substances, as well as substances with unidirectional effects on human organs, in all nearest sls, have values less than 1.0, which corresponds to a minimum level of risk of harmful effects. The risk to public health from exposure of harmful chemical substances is estimated as permissible/acceptable on the isoline that does not go beyond the minimum standard size of the plant's SPZ - $5000 \mathrm{~m}$, which does not require management solutions. 


\section{Discussion.}

This discussion uses not only results of survey undertaken, but also KAPE LLC experience in conducting a public health risk assessment to determine the SPZ size for multiple companies.

Currently, to determine an enterprise's SPZ size, calculated surface concentrations are compared with 2 criteria by impact on public health:

* hygienic standards: by a single and daily average maximum permissible concentrations (MPC m.o.t., MPC.d.a);

* reference levels of acute ARFC or chronic RFC exposure.

The MPC and RFC values of the same substances have significant differences, especially for metal compounds, although both indices are criteria for exposure to human health. The compositions of substances in unidirectional/cumulative effect groups are also different in these two systems.

As an example, we compared the quantitative values of MPC and RFC for the priority substances of the plant (Table 9).

Table 9

Quantitative Values of MPC and RFC for Plant's Priority Substances in the Air, $m g / m 3$

\begin{tabular}{|c|c|c|c|c|c|c|}
\hline Substances & MPC m.o.t. & MPC d.a. & RFC & ARFC & $\begin{array}{c}\text { MPC } \\
\text { m.o.t./ARFC }\end{array}$ & MPC d.a./ RFC \\
\hline Soot & 0.15 & 0.05 & 0.05 & ---- & 3 & 1 \\
\hline Benz / a / pyrene & ---- & $1 * 10-6$ & $1 * 10-6$ & ---- & ---- & 1 \\
\hline Sulfur dioxide & 0.5 & 0.05 & 0.08 & 0.66 & 0.76 & 0.625 \\
\hline Nitrogen dioxide & 0.2 & 0.04 & 0.04 & 0.47 & 0.43 & 1 \\
\hline Nitric oxide & 0.4 & 0.06 & 0.06 & 0.72 & 0.56 & 1 \\
\hline Carbon oxide & 5 & 3 & 5 & 23 & 0.22 & 0.6 \\
\hline
\end{tabular}

Of 40 substances identified as part of the plant's emissions using EPA procedure (USA), 14 substances have effects on the respiratory system during acute inhalation exposure, 19 substances with chronic inhalation effects. However, according to hygiene standards (MPC), each cumulative group contains no more than 3 substances (without outlining exposure direction to organs). In fact, effect of the combined impact of substances on the respiratory system is underestimated in cumulative groups .

The current situation regarding the criteria for impact on human health when determining the SPZ size is problematic; it raises many questions, and does not allow to take a sound decision on correct definition of SPZ size.

To determine the SPZ size and boundaries of an industrial facility, regarding the impact on human health, it would be advisable to use one criterion.

Era-Risks software, during the graphic presentation of simulation results of dispersion of acute non-carcinogenic and chronic non-carcinogenic substances, sums the harmful effects. Presentation of data over the outer contour of graphic lines seems to be more accurate.

It has been established that Era-Risks version of Era-Air software package, acute noncarcinogenic effects of pollutants on public health are assessed under standard (regular) conditions of enterprise's operation. However, this is not consistent with the understanding of acute non-carcinogenic effects interpreted in the Manual (Section 5.3.2) [12], which means short-term impacts ( bulk emissions or accidental releases), lasting from 5-30 minutes to 6-8 and 24 hours. Safe/reference acute exposure levels (ARFC $\mathrm{mg} / \mathrm{m}^{3}$ ) are also set based on the assumption "... that repeated acute exposure to the population is unacceptable or the time of its possible onset is many times longer than the rehabilitation period", i.e. abnormal operating conditions are implied. The short-term exposure in the Manual [12] was estimated from 5 minutes to 24 hours, which in our opinion, is too long timing interval to assess exposure using a single ARFC quantitative value. It would be advisable to differentiate the values of reference 
concentrations for ARFC acute inhalation exposures outlined in Appendix 2 of the Manual [12], depending on the duration of exposure.

Report on Era-Risks software calculation: it would be advisable to make up in accordance with the classical procedure for risk assessment performance, which includes 4 stages:

- $\quad$ 1. Identification of emissions hazard from a designed enterprise.

- 2. Assessment of the 'dose-response' relationship: identification of quantitative relationships between exposure levels and health indices (MR, 2004).

- 3. Impact (exposure) assessment of chemical substances on human health.

- $\quad$ 4. Risk profile.

\section{Recommendations.}

Assessment of public health risk when determining the SPZ size, including the software calculations, is based mainly on Manual 2.1.10.1920-04. However, this document is extremely insufficient to address this problem. It shall be required to develop a more specific and substantiated regulatory and methodological document, on the basis of which it is needed to improve the software .

$$
* * *
$$

1. Exposure risk assessment to public health of chemical environmental factors. Guidelines, Almaty, 2004. Pg. 42.

2. Guidelines to assess the risk to public health of chemical environmental factors Approved by Order of Chairperson of the State Sanitary and Epidemiological Supervision Committee of the Ministry of Public Health of the Republic of Kazakhstan No. 117 of December 28, 2007 - INVALID.

3. Order of Chairperson - Chief State Sanitary Doctor of the Republic of Kazakhstan No. 71 of September 13, 2006 'On approval of a unified methodology for all organizations entitled to conduct a risk assessment, and the Rules to conduct a risk assessment' - INVALID.

4. Risk Assessment in the Federal Government: Process Management, Washington D.C., 1983.

5. Sanitary Rules and Regulations 23-03-2003 (updated version) Sound/Noise Protection. Sanitary Regulations 51.13330.201111 (as amended N 1).

6. Sanitary Rules and Regulations 1.2.2353-08 "Carcinogenic factors and basic requirements for the prevention of carcinogenic hazards".

7. On approval of Sanitary Rules and Regulations "Sanitary and epidemiological requirements for establishment of a sanitary protection zone of industrial facilities" . Order of the Republic of Kazakhstan Minister of National Economy No. 237 dated March 20, 2015).

8. GOST 31295.1- 2005 SOUND/Noise. Sound attenuation during distribution at site. Part 1. Calculation of sound absorption by the atmosphere

9. Oder of the Republic of Kazakhstan Ministry of Environmental Protection No. 221 dated June 12, 2014. Concerning approval of certain methodological documents in the field of environmental protection.

10. Risk assessment procedure to public health from environmental pollution, approved by Order of the Minister of Environmental Protection No. 139-p dated 06.06.2008. INVALID.

11. Procedure for determining the size of the sanitary protection zone for production, processing and refining complexes of the oil and gas industry - approved by Order of Chairperson of the Committee for the State Sanitary and Epidemiological Surveillance of the Republic of Kazakhstan No. 265 dated October 15, 2010.

12. Manual to assess public health risk from chemical substances impact polluting the environment. Manual 2.1.10.1920-04 - Approved by G.G. ONISHCHENKO, Chief State Sanitary Doctor of the Russian Federation, First Deputy Minister of Public Health of the Russian Federation as of March 05, 2004.

\section{Salihova K.M. \\ To the issue of glaucoma incidence in the population of Baku city \\ Azerbaijan State Institute of Improvement of doctors named after A.Aliyev \\ (Azerbaijan, Baku)}

doi: 10.18411/scienceconf-09-2019-24

idsp: scienceconf-09-2019-24

\section{Abstract}

The observation was carried out on the basis of outpatient clinics of Yasamal district of Baku. Complete coverage information was collected on all cases of glaucoma for the 2016 